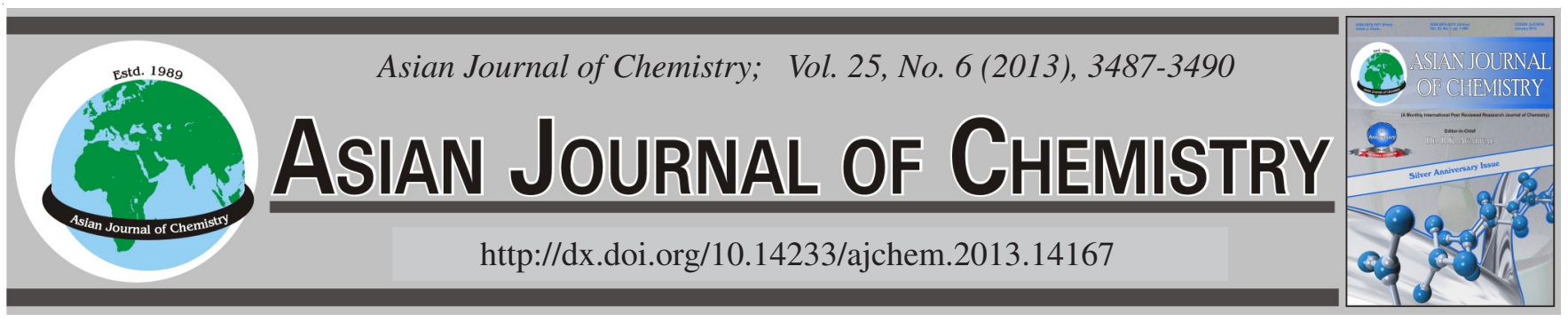

\title{
Determination of Manganese in Welded Joint and Pipe Body of API X100 Grade SAWH and SAWL Pipe for Gas Pipeline Transportation Systems
}

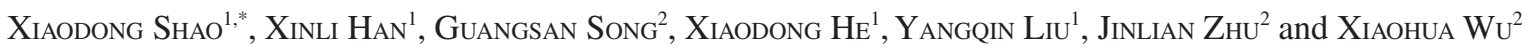

${ }^{1}$ CNPC Tubular Goods Research Institute, No. 32 Dianzier Road, Xi'an 710065, P.R. China

${ }^{2}$ Zhenjiang Entry-Exit Inspection and Quarantine Bureau, No. 84 Dongwu Road, Zhenjiang 212008, P.R. China

*Corresponding author: E-mail: shaoxd@163.com

(Received: 6 June 2012;

Accepted: 27 December 2012)

AJC-12620

\begin{abstract}
With the rapid development of economy, the demands of oil and gas are further increased. Pipeline system is the main form of transportation for natural gas. The high strength pipe line steels will become the preferred materials for modern natural gas transmission pipeline. It was well known that manganese is an important element in the high strength pipe line steels. In this paper, a simple spectrophotometric method was described for the determination of manganese in X100 grade submerged-arc welding longitudinal steel pipe. The method was based on the oxidation-reduction reaction between ammonium persulphate and manganese(II) producing manganese(VII) in the presence of silver nitrate as a catalyst. The characteristic wavelength of maximum absorption of manganese(VII) was obtained locating at $530 \mathrm{~nm}$. Under the optimum reaction conditions the absorption value was proportional to the concentration of manganese in the range of $0.18-2.0$ $\%\left(\mathrm{R}^{2}=0.9997\right)$ and the relative standard deviation was less than $3.0 \%(\mathrm{n}=5)$. The proposed method was applied successfully to determine manganese in welded joint and pipe body of X100 grade submerged-arc welding helical and submerged-arc welding longitudinal steel pipe samples.
\end{abstract}

Key Words: Manganese, Spectrophotometry, X100 grade SAW steel pipe, Welded joint.

\section{INTRODUCTION}

With the rapid development of economy, the demands of oil and gas are further increased. Pipeline system is the main form of transportation for natural gas. To improve transportation efficiency, reduce project investment, long-distance transportation of oil and natural gas pipeline has the trend to high strength steels. The use of high strength pipe line steels is beneficial for the reduction the cost of gas transmission pipelines by enabling high pressure transmission of large volumes of gas. The high strength pipe line steels can also improve the security of long-distance transmission effectively. Thus, the high strength pipe line steels will become the preferred materials for modern natural gas transmission pipeline ${ }^{1}$. In particular, high strength pipe line materials with the yield strength of X80 grade or higher have been developed over the past few decades around the world. With the second West-East Natural Gas Transmission Pipeline Project accomplished in china, an $\mathrm{X} 100$ operation trail will be constructed recently. With a much wider application anticipation of X100 pipe line being recognized increasingly, a lot of researches that conducted to speed up the process of industry production and pipeline construction, focus on chemical composition design, steel rolling technology, strength and toughness of material, the effect of strain ageing, field weld-ability, strain-based design or strain capacity of pipe line and so on ${ }^{2,3}$. And X100 grade pipe line has been developed in Japan Nippon Steel, Europipe and other companies. China West-East Natural Gas Transmission Pipeline Project has been completed for the X70 grade submerged-arc welding helical (SAWH) and submerged-arc welding longitudinal (SAWL) steel pipe ${ }^{4}$, the second West-East Natural Gas Transmission Pipeline Project mainly steel pipe is the X80 grade SAWH and SAWL steel pipe. The alloying of steel with several metallic elements plays an important role for improving the mechanical and chemical properties such as strength, toughness, heat resisting and corrosion resistance. In steel-making processes, the content of alloyed elements such as manganese, chromium, nickel, molybdenum, vanadium, titanium and niobium etc., is required to be strictly controlled because it fundamentally determines the performance of steel materials. Therefore, a rapid and precise analytical method is essentially required for the production control of manufactured steels. It was well known that manganese was an important element in the high strength pipe line steels. Manganese is valuable alloying agents and coexists in a number of industrially important alloys and steels. Owing to their increasing industrial applications of manganese, the determination of trace amounts 
of manganese is of great interest. Therefore, it was important from the analytical point of view to develop simple, sensitive and reliable methods for the determination of manganese in various complex matrixes.

Numerous analytical methods were employed for the determination of manganese in different types of matrices including atomic emission spectrophotometry ${ }^{5,6}$, atomic absorption spectrometry ${ }^{7-10}$, laser induced breakdown spectroscopy ${ }^{11,12}$ atomic fluorescence spectroscopy ${ }^{13}$, neutron activation analysis $^{14}$, electroanalytical method ${ }^{15}$ and spectrophotometry ${ }^{16-20}$. Spectrophotometric methods occupy special position due to their simplicity, less expensive instrumentation and high sensitivity. Similarly, spectrophotometric methods also play an important role in manganese determination. The literatures shows that aromatic amines, azo dyes, oximes, porphyrins and other reagents have been used for the colorimetric determination of manganese. The most significant reagents are permanganate, formaldoxime and 1-(2-pyridylazonaphthol), which is far more sensitive than the other two reagents. The present method was based on the oxidation-reduction reaction between ammonium persulphate and manganese(II). Employing ammonium persulphate as an oxidant, manganese(II) was oxidized to manganese(VII) in the presence of silver nitrate as a catalyst at the room temperature. The characteristic wavelength of maximum absorption was measured at $530 \mathrm{~nm}$. Under the optimum reaction conditions the absorption value (A) was proportional to the concentration of manganese in the range of $0.18-2.0 \%$ (mass fraction) and the relative standard deviation (RSD) was less than $3 \%(n=5)$. The proposed method was free from the interference from a large number of analytical important elements and has been applied satisfactorily to the determination of manganese in welded joint and pipe body of X100 grade submerged-arc welding helical and submerged-arc welding longitudinal steel pipe samples with the improved accuracy and precision. Results were in agreement with those attained by inductively coupled plasma atomic emission spectrophotometry at the $95 \%$ confidence level. The satisfactory performance in the determination of manganese in X100 grade SAWH and SAWL steel pipe demonstrated that the method was practical and suitable not only for quality control analysis but also for product analysis, confirming the promise for X100 grade SAWH and SAWL steel pipe research.

\section{EXPERIMENTAL}

A UV-visible spectrophotometer (Model TU-1901, Beijing Persee General Instrument Co. Ltd.) with $1.0 \mathrm{~cm}$ quartz cells was employed for all absorbance measurements.

All chemicals including sulphuric acid, nitric acid (Xi'an Chemical Reagent Plant) and phosphoric acid (Sichuan Xilong Chemical Co. Ltd.) used in the experiments were of analytical reagent grade and were used as received. Solutions of ammonium persulphate, sodium nitrite (Xi'an Chemical Reagent Plant) and silver nitrate (Institute of Shanghai Fine Chemical Materials) were prepared daily by dissolving the reagents in deionised water that treated with a Milli-Q water purification system (Millipore, Bedford, MA, USA). Solutions of manganese were prepared from the steel certified reference materials (CRM) including GBW 01301, GBW 01302, GBW 01305, GBW
01307, GBW 01311, GBW 01312 (Institute of Anshan Iron and Steel Group Corporation), GBW 01354 (Institute of Fushun Iron and Steel Group Corporation), GBW 01358 (Shanghai Iron and Steel Institute) and GSBH 40084(China Iron \& Steel Research Institute Group). All working strength solutions in the experiment were prepared with deionized water.

General procedures: Weigh accurately $0.1 \mathrm{~g}$ of drilled low alloy steel samples and dissolve the samples in $20 \mathrm{~mL}$ mixture acid solution of sulphuric acid $15 \%$ (v/v) and phosphoric acid $15 \%(\mathrm{v} / \mathrm{v})$ in a $150 \mathrm{~mL}$ taper bottle. Continue the treatment with mixture acid till the sample goes into solution and heat to fumes of oxides of nitrogen, sulphuric acid and evaporate almost to dryness. Cool the solution, add $50 \mathrm{~mL}$ deionised water to dissolve some materials. Then, add $5 \mathrm{~mL}$ of $5 \mathrm{mg} \mathrm{mL}^{-1}$ solution of silver nitrate, $10 \mathrm{~mL}$ of $200 \mathrm{mg} \mathrm{mL}^{-1}$ solution of ammonium persulphate in the taper bottle to oxidate manganese(II) to manganese(VII) oxidation states. Boil the solution to no bubble and cool the solution at room temperature. Finally, dilute the solution in a $100 \mathrm{~mL}$ volumetric flask, followed make up to the mark with deionized water, mix well and let stand for $10 \mathrm{~min}$. Then, transfer the above mulberry stock solution in $1 \mathrm{~cm}$ quartz cells. Add $5 \mathrm{mg} \mathrm{mL}^{-1}$ solution of sodium nitrite to the remaining solution reduce manganese(VII) to the lower oxidation states, this transparent solution was employed as the blank solution in subsequent experiments. Measure the absorbance at $530 \mathrm{~nm}$ using a UV-visible spectrophotometer with $1 \mathrm{~cm}$ quartz cells against a reagent blank prepared similarly. Plot the amount of manganese in the sample solution against absorbance to obtain the calibration graph.

\section{RESULTS AND DISCUSSION}

Spectral characteristics: The absorption spectra of the reagents blank, manganese(VII) against the reagent blank were tested from 400-700 $\mathrm{nm}$. The manganese(VII) yields the characteristic wavelength of maximum absorption at $530 \mathrm{~nm}$ wavelength. However, the absorption spectrum of the reagents blank under similar conditions shown that it does not absorb at $530 \mathrm{~nm}$. And the experimentation also demonstrated that manganese(VII) increases the absorbance value considerably, resulting in increased sensitivity of the method. Therefore, measure the absorbance of manganese(VII) at $530 \mathrm{~nm}$.

Select dissolved acid for low alloy steel samples: The effect of the different acids for dissolve the low alloy steel samples was examined. It was found that a solution mixed with $15 \%(\mathrm{v} / \mathrm{v})$ sulphuric acid and $15 \%(\mathrm{v} / \mathrm{v})$ phosphoric acid has a good effect for dissolve the low alloy steel samples. Thus, an acid solution mixed with $15 \%$ (v/v) sulphuric acid and $15 \%(\mathrm{v} / \mathrm{v})$ phosphoric acid was recommended for dissolve the low alloy steel samples in subsequent studies.

Influence of the amounts of oxidant: Ammonium persulphate was selected as the oxidant in the proposed method. The effect of the oxidant was examined by measuring the absorbance of solution containing certain amounts of manganese(II) and variable amounts of ammonium persulphate. It was found that $10 \mathrm{~mL}$ of $200 \mathrm{mg} \mathrm{mL}^{-1}$ solution of ammonium persulphate sufficed to oxidate the amounts of manganese(II) taken, with higher concentrations the absorbance was essentially constant. 
Ten millilitres of $200 \mathrm{mg} \mathrm{mL}^{-1}$ ammonium persulphate solution were recommended as a suitable amount of oxidant.

Influence of the amounts of silver nitrate: The oxidationreduction reaction between manganese(II) and ammonium persulphate without a catalyst was slowly and not fully. Selected the silver nitrate as a catalyst for the oxidationreduction reaction between manganese(II) and ammonium persulphate. It has been further observed that the oxidationreduction reaction between manganese(II) and ammonium persulphate occurs immediately even at room temperature if silver nitrate was used. Therefore, $5 \mathrm{~mL}$ of $5 \mathrm{mg} \mathrm{mL}^{-1}$ solution of silver nitrate was employed in subsequent experiments.

Influence of the reductant: Sodium nitrite was selected as the reductant in the proposed method. $5.0 \mathrm{mg} \mathrm{mL}^{-1}$ solution of sodium nitrite reduce manganese(VII) to the lower oxidation states manganese(II). The transparent solution was employed as the blank solution in subsequent experiments.

Sequence of addition of reagents: From experiments in which sulphuric acid, phosphoric acid, ammonium persulphate and silver nitrate were added in all possible orders. It was found that there was no appreciable change in the colour of the solution and the variations in the absorbance values. These phenomenons demonstrate that the oxidation-reduction reaction between manganese(II) and ammonium persulphate was independent of the order of addition.

Preparation of the calibration graph: Under the optimal conditions, a series of standard solutions of manganese were prepared by the different steel certified reference materials in a $100 \mathrm{~mL}$ volumetric flask. Add $5 \mathrm{~mL}$ of $5 \mathrm{mg} \mathrm{mL}^{-1}$ solution of silver nitrate, $10 \mathrm{~mL}$ of $200 \mathrm{mg} \mathrm{mL}^{-1}$ solution of ammonium persulphate followed make up to the mark with deionized water, mix well and let stand for $10 \mathrm{~min}$. Measure the absorbance at $530 \mathrm{~nm}$ using a UV-visible spectrophotometer with $1.0 \mathrm{~cm}$ quartz cells against a reagent blank. The absorbance of the solution was proportional to the concentration of manganese in the range of $0.18-2.0 \%$ (mass fraction). Plot the amount of manganese in the sample solution against absorbance to obtain the calibration graph. The linear regression equation for manganese was $\mathrm{A}=0.41837 \mathrm{C}-0.01073, \mathrm{R}^{2}=0.9997$ and the relative standard deviation (RSD) was less than $3.0 \%(n=5)$.

Interference studies: The extent of interference by diverse ions was determined by measuring the absorbance of solutions containing manganese and various amounts of diverse ions. The criterion for interference was an absorbance value varying by more than $\pm 2 \%$ from the expected value of manganese alone. The results show that a large excess of cations and anions which are usually associated in the determination of manganese do not interfere. The colourless metal ions do not interfere. The tolerable amounts of foreign species with respect to manganese for interference at $\pm 2 \%$ level were over 200-300 for the coloured metal ions. When the coloured metal ions contents of not more than 200-300 times manganese, it can be in some colour solution adding a few drops of EDTA solution or sodium nitrite solution to fade the colour, this solution as the measured reference solution to eliminate the interference. There was not obvious interference ions exist in X100 grade SAWH and SAWL steel pipe samples.

\section{Applications}

Determination of manganese in pipe body of X100 grade SAWH and SAWL steel pipe samples: The recommended procedure has been applied satisfactorily to the determination of manganese in pipe body of X100 grade SAWH and SAWL steel pipe samples. The samples were dissolved according to the following procedure: Dissolve $0.1 \mathrm{~g}$ of drilled X100 grade SAWH and SAWL steel pipe samples in $20 \mathrm{~mL}$ mixture acid solution of sulphuric acid $15 \%$ (v/v) and phosphoric acid 15 $\%(\mathrm{v} / \mathrm{v})$ in a $150 \mathrm{~mL}$ taper bottle. Continue the treatment with mixture acid till the sample goes into solution and heat to fumes of oxides of nitrogen, sulphuric acid and evaporate almost to dryness. Cool the solution, add $50 \mathrm{~mL}$ deionised water to dissolve some materials. Then, add $5 \mathrm{~mL}$ of $5 \mathrm{mg} \mathrm{mL}^{-1}$ solution of silver nitrate, $10 \mathrm{~mL}$ of $200 \mathrm{mg} \mathrm{mL}^{-1}$ solution of ammonium persulphate in the taper bottle to oxidate manganese(II) to manganese(VII) oxidation states. Boil the solution to no bubble and cool the solution at room temperature. Finally, dilute the solution in a $100 \mathrm{~mL}$ volumetric flask, followed make up to the mark with deionized water, mix well and let stand for 10 min. Then, transfer the above mulberry stock solution in $1 \mathrm{~cm}$ quartz cells. Add $5 \mathrm{mg} \mathrm{mL}^{-1}$ solution of sodium nitrite to the remaining solution reduce manganese(VII) to the lower oxidation states, this transparent solution was employed as the blank solution in subsequent experiments. Measure the absorbance at $530 \mathrm{~nm}$ using a UV-visible spectrophotometer with $1 \mathrm{~cm}$ quartz cells against a reagent blank. The results were summarized in Table- 1 with the good accuracy and precision. To verify the results obtained by the proposed method, inductively coupled plasma atomic emission spectrophotometry method was applied to determine the samples according to the literature and the results obtained by the proposed method agreed well with that from the reference method.

Determination of manganese in welded joint of X100 grade SAWH and SAWL steel pipe samples: The proposed method was also applied successfully to the determination of manganese in welded joint of X100 grade SAWH and SAWL steel pipe samples. Weigh accurately $0.1 \mathrm{~g}$ of drilled API grade $\mathrm{X} 70$ pipe line steel samples in $20 \mathrm{~mL}$ mixture acid solution of sulphuric acid $15 \%(\mathrm{v} / \mathrm{v})$ and phosphoric acid $15 \%(\mathrm{v} / \mathrm{v})$ in a $150 \mathrm{~mL}$ taper bottle. Continue the treatment with mixture acid till the sample goes into solution and heat to fumes of oxides of nitrogen, sulphuric acid and evaporate almost to dryness. Cool the solution, add $50 \mathrm{~mL}$ deionized water to dissolve some materials. Then, add $5 \mathrm{~mL}$ of $5 \mathrm{mg} \mathrm{mL}^{-1}$ solution of silver

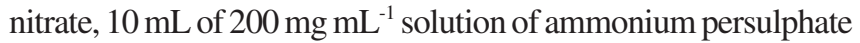
in the taper bottle to oxidate manganese(II) to manganese(VII) oxidation states. Boil the solution to no bubble and cool the solution at room temperature. Finally, dilute the solution in a $100 \mathrm{~mL}$ volumetric flask, followed make up to the mark with deionised water, mix well and let stand for $10 \mathrm{~min}$. Then, transfer the above mulberry stock solution in $1 \mathrm{~cm}$ quartz cells. Add $5 \mathrm{mg} \mathrm{mL}^{-1}$ solution of sodium nitrite to the remaining solution reduce manganese(VII) to the lower oxidation states, this transparent solution was employed as the blank solution in subsequent experiments. Measure the absorbance at 530 $\mathrm{nm}$. The measured absorbance for determination the amounts of manganese using the recommended calibration graph and the results were given in Table-2. The concentrations of manganese determined by the proposed spectrophotometric method were compared with the concentrations of the samples from the inductively coupled plasma atomic emission spectrophotometry method. The results were in agreement with those 
TABLE-1

RESULTS OF DETERMINATION OF MANGANESE IN PIPE BODY OF X100 SAW STEEL PIPE ${ }^{a}$

\begin{tabular}{ccccccc}
\hline \multirow{2}{*}{ Sample No. } & \multirow{2}{*}{ Type } & \multirow{2}{*}{ Size $(\mathrm{mm})$} & \multirow{2}{*}{$\mathrm{A}$} & RSD $(\%)$ & \multicolumn{2}{c}{ Content $(\omega, \%)$} \\
\cline { 5 - 7 } & & & & & By the proposed method & By AES \\
\hline 1 & SAWH & $\Phi 13 \times 15.0$ & 0.7633 & 1.21 & $1.85 \pm 0.02$ & $1.84 \pm 0.03$ \\
3 & SAWH & $\Phi 1016 \times 15.3$ & 0.8180 & 0.99 & $1.98 \pm 0.02$ & $2.01 \pm 0.01$ \\
4 & SAWH & $\Phi 1219 \times 15.3$ & 0.8277 & 1.64 & $2.00 \pm 0.03$ & $1.97 \pm 0.04$ \\
5 & SAWL & $\Phi 813 \times 12.7$ & 0.7691 & 1.55 & $1.86 \pm 0.03$ & $1.86 \pm 0.02$ \\
6 & SAWL & $\Phi 813 \times 15.0$ & 0.7657 & 1.83 & $1.86 \pm 0.04$ & $1.85 \pm 0.02$ \\
7 & SAWL & $\Phi 1016 \times 14.3$ & 0.7441 & 0.57 & $1.80 \pm 0.01$ & $1.83 \pm 0.01$ \\
8 & SAWL & $\Phi 1016 \times 18.4$ & 0.7787 & 0.68 & $1.89 \pm 0.01$ & $1.90 \pm 0.03$ \\
9 & SAWL & $\Phi 1219 \times 23.5$ & 0.7130 & 2.02 & $1.73 \pm 0.03$ & $1.75 \pm 0.02$ \\
\hline${ }^{a}$ Average of five determinations. & SAWL & $\Phi 1016 \times 16.0$ & 0.8105 & 1.05 & $1.96 \pm 0.02$ & $1.94 \pm 0.01$ \\
\hline
\end{tabular}

TABLE-2

RESULTS OF DETERMINATION OF MANGANESE IN WELDED JOINT OF X100 SAW STEEL PIPE ${ }^{a}$

\begin{tabular}{ccccccc}
\hline \multirow{2}{*}{ Sample No. } & \multirow{2}{*}{ Type } & Size $(\mathrm{mm})$ & \multirow{2}{*}{$\mathrm{A}$} & \multirow{2}{*}{ RSD $(\%)$} & \multicolumn{2}{c}{ Content $(\omega, \%)$} \\
\cline { 5 - 7 } & & & & By the proposed method & By AES \\
\hline 1 & SAWH & $\Phi 813 \times 15.0$ & 0.7695 & 1.53 & $1.86 \pm 0.03$ & $1.87 \pm 0.01$ \\
3 & SAWH & $\Phi 1016 \times 15.3$ & 0.7884 & 1.04 & $1.91 \pm 0.02$ & $1.88 \pm 0.04$ \\
4 & SAWH & $\Phi 1219 \times 15.3$ & 0.8063 & 0.39 & $1.95 \pm 0.01$ & $1.95 \pm 0.01$ \\
5 & SAWL & $\Phi 813 \times 12.7$ & 0.7825 & 2.11 & $1.90 \pm 0.04$ & $1.89 \pm 0.03$ \\
6 & SAWL & $\Phi 813 \times 15.0$ & 0.7858 & 1.00 & $1.90 \pm 0.02$ & $1.94 \pm 0.03$ \\
7 & SAWL & $\Phi 1016 \times 14.3$ & 0.6997 & 1.69 & $1.70 \pm 0.03$ & $1.69 \pm 0.02$ \\
8 & SAWL & $\Phi 1016 \times 18.4$ & 0.7059 & 0.76 & $1.71 \pm 0.01$ & $1.70 \pm 0.04$ \\
9 & SAWL & $\Phi 1219 \times 23.5$ & 0.7143 & 2.31 & $1.73 \pm 0.04$ & $1.73 \pm 0.03$ \\
\hline
\end{tabular}

attained by inductively coupled plasma atomic emission spectrophotometry at the $95 \%$ confidence level.

\section{Conclusion}

Based on the oxidation-reduction reaction between manganese(II) and ammonium persulphate, a simple and accurate spectrophotometric method for determination of manganese in X100 grade submerged-arc welding helical and submerged-arc welding longitudinal steel pipe was proposed. The purple-red coloured manganese(VII) solution exhibits absorption maximum at $530 \mathrm{~nm}$. The proposed method was free from the interference from a large number of analytical important elements and has been applied satisfactorily to the determination of manganese in X100 grade submerged-arc welding helical and submerged-arc welding longitudinal steel pipe samples. Compared with other methods for the determination of manganese, this method offers advantages of simplicity, less expensive instrumentation and high efficient. The satisfactory performance in the determination of manganese in X100 grade submerged-arc welding helical and submergedarc welding longitudinal steel pipe demonstrated that the method was practical and suitable not only for quality control analysis but also for product analysis, confirming the promise for X100 grade submerged-arc welding helical and submergedarc welding longitudinal steel pipe research.

\section{ACKNOWLEDGEMENTS}

The authors gratefully acknowledged the CNPC Tubular Goods Research Institute and China National Quality Supervision, Testing and Inspection Center of Oil Tubular Goods.

\section{REFERENCES}

1. H.L. Li, China Mechanical Eng., 12, 349 (2001).

2. B. Tanguy, T.T. Luu, G. Perrin, A. Pineau and J. Besson, Int. J. Pressure Vessels Piping, 85, 322 (2008).

3. S. Nafisi, M.A. Arafin, L. Collins and J. Szpunar, Mater. Sci Eng. A, 531, 2 (2012).

4. Y.R. Feng, H. Chen, J.J. Zhang and K.G. Zhang, Oil Gas Storage Transportation, 27, 1 (2008).

5. K. Wagatsuma, K. Kodama and H. Park, Anal. Chim. Acta, 502, 257 (2004).

6. T.M. Naeem, H. Matsuta and K. Wagatsuma, Anal. Sci., 20, 1717 (2004).

7. N. Tokman, J. Hazard. Mater., 143, 87 (2007).

8. Ç.A. Sahin, M. Efeçinar and N. Satiroglu, J. Hazard. Mater., 176, 672 (2010).

9. M.A. Taher, Anal. Sci., 17, 969 (2001).

10. V.A. Lemos and G.T. David, Microchem. J., 94, 42 (2010).

11. F.B. Gonzaga and C. Pasquini, Spectrochim. Acta B, 63, 56 (2008).

12. F.B. Gonzaga and C. Pasquini, Spectrochim. Acta B, 63, 1268 (2008).

13. J.D. Norris and T.S. West, Anal. Chim. Acta, 59, 474 (1972).

14. K. Tomura and H. Tomuro, J. Radioanal. Nucl. Chem., 242, 147 (1999).

15. R. Piech, B. Basa and W.W. Kubiaka, J. Electroanal. Chem., 621, 43 (2008).

16. D. Zhang, S. Ba and J. Gao, Metallurgical Anal., 26, 44 (2006).

17. B. Chiswell and G. Rauchle, Talanta, 37, 237 (1990).

18. M. Kamburova, Talanta, 46, 1073 (1998).

19. S.G. Silva, J.A. Nóbrega and F.R.P. Rocha, Microchem. J., 98, 109 (2011).

20. S. Nakano, Y. Matumoto and M. Yoshii, Talanta, 68, 312 (2005). 